\title{
Fever, jaundice and acute renal failure
}

\author{
Authors: Sam M O'Toole, ${ }^{A}$ Neha Pathak, ${ }^{B}$ Graham C Toms, ${ }^{C}$ Susan V Gelding ${ }^{D}$ and Venkat Sivaprakasam ${ }^{\mathrm{E}}$
}

Leptospirosis is an uncommon infectious disease that has protean clinical manifestations ranging from an innocuous 'flu-like' illness to potentially life-threatening multi-organ failure. Here we describe a case of Weil's disease that presented on the acute medical take with fever, jaundice and acute renal failure. We highlight the importance of careful history taking at the time of admission and how understanding the epidemiology and pathophysiology of leptospirosis enables a definitive diagnosis to be reached.

KEYWORDS: Leptospirosis, Weil's disease, fever, jaundice, acute renal failure

\section{Case presentation}

A 52-year-old man presented with generalised myalgia, arthralgia and abdominal pain. For one week he had experienced low-grade fever, malaise and lethargy, together with rigors, drenching sweats, anorexia and unquantified weight loss. His urine had darkened, resembling 'brown ale'. The day before presenting he noticed yellowing of his sclera.

His past medical history included hypertension, a transient ischaemic attack, duodenal ulceration and an aortic valve repair and root replacement. His regular medications comprised aspirin, bisoprolol, omeprazole, ramipril and simvastatin. $\mathrm{He}$ had a distant history of recreational drug use, tattoos and a 25 pack-year smoking history. He drank alcohol occasionally and worked for drug and alcohol services. He had no known ill contacts and had not been abroad for over a year.

Clinical examination revealed normal vital observations, digital clubbing and jaundice with no stigmata of chronic liver disease. He had a median sternotomy scar and a collapsing pulse, but no murmurs or added heart sounds. The abdomen

Authors: A specialist registrar, Department of Endocrinology, Newham University Hospital, Barts Health NHS Trust, London, UK; ${ }^{B}$ academic foundation doctor, Department of Endocrinology, Newham University Hospital, Barts Health NHS Trust, London, UK; ${ }^{C}$ consultant physician, Department of Endocrinology, Newham University Hospital, Barts Health NHS Trust, London, UK; ${ }^{\mathrm{D}}$ consultant physician, Department of Endocrinology, Newham University Hospital, Barts Health NHS Trust, London, UK;

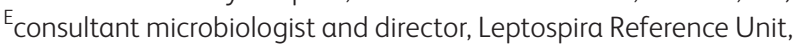
Wye Valley NHS Trust, Hereford, UK was generally tender without guarding. Both thighs were painful and tender, but not swollen. There was no rash. Initial investigations (Table 1) demonstrated neutrophil leucocytosis, lymphopaenia, thrombocytopaenia, acute renal impairment, hepatic dysfunction with obstructive jaundice and an elevated C-reactive protein. Urine dipstick was positive for blood, protein, ketones, nitrites and leucocytes. Chest radiograph and electrocardiogram were normal. Abdominal ultrasonography showed mildly enlarged unobstructed kidneys and a normal liver, biliary system and portal vein.

\section{Differential diagnosis}

The differential is wide. Infective endocarditis was initially considered. Other possible infective aetiologies include bacterial sepsis, viral hepatitis, malaria, HIV, leptospirosis, yellow fever and dengue fever, though the latter two are unlikely given the lack of travel history. Autoimmune conditions, such as thrombotic thrombocytopenic purpura or a systemic vasculitis, were also considered.

\section{Initial management}

Aggressive IV hydration was instigated and all nephrotoxic drugs were discontinued. Urine and multiple blood cultures were obtained. Other diagnostic tests performed included antinuclear antibodies (ANA), anti-neutrophil cytoplasmic antibody (ANCA), blood film, creatine kinase (CK), serology for HIV, viral hepatitis, cytomegalovirus and Epstein-Barr virus. Empirical antibiotic therapy was not commenced.

\section{Case progression}

A transthoracic echocardiogram showed mild aortic regurgitation without vegetations. Serial blood and urine cultures were sterile.

Revisiting the history revealed his symptoms had commenced ten days after a week-long fishing trip in southern England. He had camped beside a lake and handled his catch with his bare hands that bore small cuts. Leptospirosis was now the most likely diagnosis.

Intravenous ceftriaxone was commenced and his symptoms and blood tests (Table 1) improved. On day three of admission, he developed small-volume haemoptysis. Sputum microscopy and culture were negative. Autoimmune and viral screens were normal. CK was moderately elevated ( $822 \mathrm{IU} / 1$; normal range 67-440 IU/l) and normalised with fluid therapy.

A serum sample taken on illness day nine (admission day two) was negative for leptospirosis serology and polymerase 
Table 1. Serial blood investigations.

\begin{tabular}{|c|c|c|c|c|c|}
\hline Parameter & $\begin{array}{l}\text { Reference } \\
\text { range }\end{array}$ & $\begin{array}{l}\text { Day of } \\
\text { admission }\end{array}$ & $\begin{array}{l}\text { Admission } \\
\text { day } 5\end{array}$ & $\begin{array}{l}\text { Admission } \\
\text { day } 11\end{array}$ & $\begin{array}{l}\text { Six weeks post } \\
\text { discharge }\end{array}$ \\
\hline Haemoglobin, g/dl & $12.5-17.5$ & 13.5 & 10.8 & 10.3 & 13.2 \\
\hline MCV, fl & $78-96$ & 86.8 & 85.8 & 88.4 & 88.5 \\
\hline WCC, $\times 10^{9} /$ I & $4.0-11.0$ & 13.5 & 18.7 & 8.5 & 10.6 \\
\hline Neutrophils, $\times 10^{9} / /$ & $2.5-7.5$ & 12.8 & 15.0 & 5.9 & 7.4 \\
\hline Lymphocytes, $\times 10^{9} / /$ & $1.5-4.0$ & 0.3 & 1.8 & 1.7 & 2.2 \\
\hline Platelets, $\times 10^{9} / /$ & $140-450$ & 75 & 341 & 783 & 355 \\
\hline INR & $0.8-1.1$ & 1.1 & 1.1 & 1.0 & 1.0 \\
\hline APTT, secs & $20-30$ & 30 & 24 & 25 & - \\
\hline Sodium, mmol/l & $133-146$ & 135 & 136 & 140 & 140 \\
\hline Potassium, $\mathrm{mmol} / \mathrm{l}$ & $3.5-5.3$ & 4.0 & 4.3 & 4.8 & 4.3 \\
\hline Urea, mmol/l & $3.3-6.7$ & 26.0 & - & - & - \\
\hline Creatinine, $\mu \mathrm{mol} / \mathrm{l}$ & $62-106$ & 353 & 131 & 101 & 105 \\
\hline Bilirubin, $\mu \mathrm{mol} / /$ & $5-21$ & 224 & 123 & 51 & 20 \\
\hline ALP, IU/I & $30-130$ & 268 & 204 & 158 & 84 \\
\hline ALT, IU/I & $<45$ & 45 & 202 & 159 & 19 \\
\hline Albumin, g/l & $35-50$ & 35 & 29 & 38 & 43 \\
\hline CRP, mg/l & $<10$ & 134 & 24 & 2 & - \\
\hline
\end{tabular}

$\mathrm{ALP}=$ alkaline phosphatase; $\mathrm{ALT}=$ alanine aminotransferase; $\mathrm{APTT}=$ activated partial thromboplastin time; $\mathrm{CRP}=$ complement reactive protein; $\mathrm{INR}=$ international normalised ratio; $\mathrm{MCV}=$ mean corpuscular volume; $\mathrm{WCC}=$ white cell count.

chain reaction (PCR) (Table 2). Nonetheless, ceftriaxone was continued as the clinical suspicion for leptospirosis was high. Following discussion with the Leptospira Reference Unit, a second serum sample was taken on illness day 16 (admission day nine). This confirmed leptospirosis with clear seroconversion in the IgM enzyme-linked immunosorbent assay (ELISA). However, the microscopic agglutination test (MAT) remained negative.

He received ten days of IV ceftriaxone followed by seven days of oral doxycycline. At follow-up six weeks later, his symptoms had completely resolved and all blood tests had normalised (Table 1). A convalescent serum sample was MAT positive with high titres against serogroup icterohaemorrhagiae.

\section{Discussion}

Leptospirosis is a zoonosis caused by spirochetes (genus Leptospira) that infect humans through contact with water or soil contaminated with the urine of reservoir host animals (usually rodents). Infection is more common during heavy rainfall due to stagnant water. This explains its seasonality in temperate climates (Fig 1) and increased prevalence in the tropics (up to $10-100$ cases per 100,000 population). ${ }^{1}$ Only 44 cases were reported in England and Wales in 2011, where it may be underdiagnosed. Most are indigenously acquired. ${ }^{2}$

Risk factors for infection (Table 3) are related to Leptospira exposure and highlight the importance of a thorough occupational and recreational history. In this case, revisiting the history was crucial to reaching the diagnosis.
Infection is biphasic with an incubation period of 2-30 days (usually 5-14) preceding a flu-like illness. This may progress to aseptic meningitis, pulmonary haemorrhage, myocarditis or, as in this case, jaundice and renal failure (Weil's disease). Complications generally occur during the immune phase or later disease stages. This patient unusually presented with complications before the immune phase (Tables 1 and 2), probably due to the virulence of the organism. Mortality rates vary from no reported fatal cases in England and Wales in $2011^{2}$ to a $17 \%$ case fatality rate in a Turkish series between 1991 and 2002. ${ }^{3}$ Long-term health sequelae are rare.

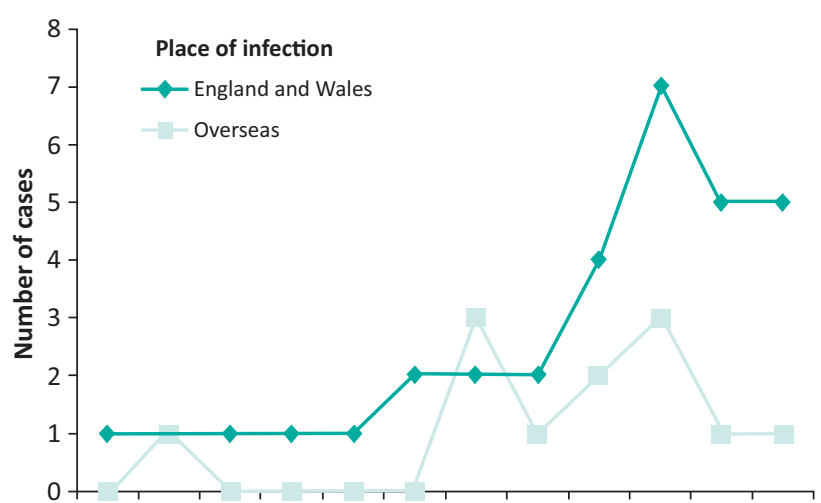

Jan Feb Mar Apr May Jun Jul Aug Sep Oct Nov Dec

Fig 1. Indigenous and imported leptospirosis cases in England and Wales in 2011. 
Table 2. Leptospira serology.

\begin{tabular}{lllll} 
Timing & $\begin{array}{l}\text { Admission day 2, } \\
\text { illness day } \mathbf{9}\end{array}$ & $\begin{array}{l}\text { Admission day 9, } \\
\text { illness day } \mathbf{1 6}\end{array}$ & $\begin{array}{l}\text { Admission day 11, } \\
\text { illness day 18 }\end{array}$ & Four weeks post discharge \\
IgM ELISA & Negative & $1: 640$ & $1: 640$ & $1: 80$ \\
MAT & Negative & Negative & $1: 40$ & $1: 160$ \\
DNA PCR & Negative & - & Leptospira icterohaemorrhagiae \\
\hline ELISA = enzyme-linked immunosorbent assay; MAT = microscopic agglutination test; PCR = polymerase chain reaction.
\end{tabular}

Diagnosis can be delayed as leptospirosis may not be considered and confirmation of infection depends on the timing of samples taken. Leptospira organisms can be visualised in infected fluids using dark field microscopy, but expertise in this technique is limited. Culture takes up to six weeks, making it impractical for clinical diagnosis. The mainstay of diagnosis is serology which requires knowledge of the natural history of infection and depends on the patient's immune response. Paired acute and convalescent samples are necessary. The gold-standard diagnostic test remains the MAT in which serum is exposed to live Leptospira. This is time-consuming, technically demanding and, in the UK, only available at the Leptospira Reference Unit in Hereford. IgM ELISAs, which become positive earlier, are useful screening assays. Leptospira. DNA can be identified by PCR. This is a useful adjunct, particularly in early infection, as leptospiraemia occurs before the appearance of antibodies in the blood (at which point the PCR becomes negative). In our patient both the IgM ELISA and PCR were negative on illness day nine. This could be because the initial antibody response was sufficient to neutralise the leptospires but inadequate for IgM ELISA detection. He was apparently in transition from leptospiraemia to seroconversion. Knowledge of the dynamics of leptospirosis is therefore essential for selecting appropriate diagnostic tests at different clinical stages.

Standard management is prompt commencement of antimicrobials as confirmation of diagnosis is often delayed. However, a recent Cochrane review found insufficient evidence to support antibiotic use, particularly in severe disease. ${ }^{4}$ Mild cases can be treated with oral amoxicillin, ampicillin, doxycycline or erythromycin. Severe cases, as in this patient, should receive IV penicillin, a third-generation cephalosporin or a quinolone. Methylprednisolone, plasma exchange with cyclophosphamide and extra-corporeal membrane oxygenation have been used, particularly when alveolar haemorrhage occurs. The most severe cases may require ITU admission for organ support.

\section{Table 3. Risk factors for leptospirosis. ${ }^{5}$}

$\begin{array}{ll}\text { Risk } & \text { Exposure } \\ \text { Occupational } & \begin{array}{l}\text { Farmers, abattoir workers, veterinarians, sewer } \\ \text { workers, military personnel and laboratory } \\ \text { staff }\end{array} \\ \text { Recreational } & \begin{array}{l}\text { Fresh water swimming, fishing, canoeing, } \\ \text { triathletes, surfers and rowers }\end{array} \\ \text { Domestic } & \text { Rodent infestations and pet dogs }\end{array}$

\section{Learning points}

> Detailed history taking and revisiting the history with renewed information is essential where a diagnosis is uncertain.

$>$ Where clinical suspicion of a particular diagnosis is high but initial investigations are non-confirmatory, it is important to discuss the case with experts, to establish appropriate samples for appropriate tests based on the timescale of events.

$>$ Ensuring all relevant clinical information, including the time course of the illness, accompanies every sample sent for specialist investigations facilitates appropriate testing (PCR or serology or both) and timely generation of results.

$>$ The often non-specific clinical and laboratory features of leptospirosis mean that knowledge of its epidemiological associations are integral to its consideration and prompt diagnosis.

> Leptospirosis is a rare, but potentially life-threatening disease that often presents with non-specific clinical features and should be considered in patients with known risk factor exposure as demonstrated in this case report.

$>$ Complications of leptospirosis can occur at the early leptospiraemic phase; it is important to use molecular techniques for prompt diagnosis and initial management, thereby reducing the severity of complications.

\section{References}

1 World Health Organization. Human leptospirosis: guidance for diagnosis, surveillance and control. Geneva: WHO, 2003. Available online at http://whqlibdoc.who.int/hq/2003/WHO_CDS_CSR_ EPH_2002.23.pdf [Accessed 20 November 2014].

2 Health Protection Agency. Leptospira infections in 2011. Available online at http://webarchive.nationalarchives.gov.uk/20140714084352/ http://www.hpa.org.uk/Topics/InfectiousDiseases/InfectionsAZ/ Leptospirosis/EpidemiologicalData/lepto004EpiData2011/ [Accessed 20 November 2014].

3 Esen S, Sunbul M, Leblebicioglu H, Eroglu C and Turan D. Impact of clinical and laboratory findings on prognosis in leptospirosis. Swiss Med Wkly 2004;134:347-52.

4 Bret-Major DM and Coldren R. Antibiotics for leptospirosis. Cochrane Database Syst Rev 2012 2:CD008264.

5 Nick Day. Epidemiology, microbiology, clinical manifestations, and diagnosis of leptospirosis. UpToDate, 10 July 2014. Available online at www.uptodate.com/contents/epidemiology-microbiology-clinicalmanifestations-and-diagnosis-of-leptospirosis (22 December 2014).

Address for correspondence: Dr SM O'Toole, Newham University Hospital, Glen Road, Plaistow, London E13 8SL, UK. Email: samuel.otoole2@bartshealth.nhs.uk 